TI 2011-017/1

Tinbergen Institute Discussion Paper

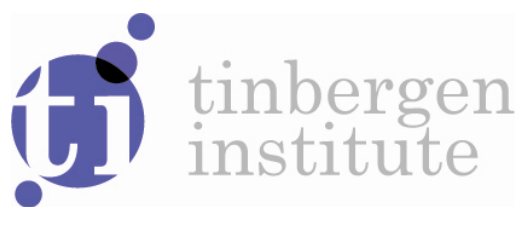

\title{
Inverse Adverse Selection: The Market for Gems
}

Giuseppe Dari-Mattiaccil

Sander Onderstal

Francesco Parisi

' University of Amsterdam, and Tinbergen Institute;

2 University of Minnesota, and University of Bologna. 
Tinbergen Institute is the graduate school and research institute in economics of Erasmus University Rotterdam, the University of Amsterdam and VU University Amsterdam.

More TI discussion papers can be downloaded at http://www.tinbergen.nl

Tinbergen Institute has two locations:

Tinbergen Institute Amsterdam

Gustav Mahlerplein 117

1082 MS Amsterdam

The Netherlands

Tel.: +31(0)205251600

Tinbergen Institute Rotterdam

Burg. Oudlaan 50

3062 PA Rotterdam

The Netherlands

Tel.: +31(0)10 4088900

Fax: +31(0)104089031

Duisenberg school of finance is a collaboration of the Dutch financial sector and universities, with the ambition to support innovative research and offer top quality academic education in core areas of finance.

DSF research papers can be downloaded at: http://www.dsf.nl/

Duisenberg school of finance

Gustav Mahlerplein 117

1082 MS Amsterdam

The Netherlands

Tel.: +31(0)20 5258579 


\title{
Inverse Adverse Selection: The Market for Gems*
}

\author{
Giuseppe Dari-Mattiacci ${ }^{\dagger} \quad$ Sander Onderstal ${ }^{\ddagger}$ \\ Francesco Parisi ${ }^{\S}$
}

August 17, 2010

\begin{abstract}
This paper studies markets plagued with asymmetric information on the quality of the goods traded. In Akerlof's setting, sellers are better informed than buyers. In contrast, we examine cases where buyers are better informed than sellers. This creates an inverse adverse-selection problem: The market tends to disappear from the bottom rather than from the top. In contrast to the traditional model, it is the high-value goods (gems) that remain longer on the market, rather than the lowvalue goods (lemons). We investigate the consequences of this inverse adverse-selection and its potential solutions. The uninformed buyer in a traditional market for lemons experiences the qualities of the good he purchased; instead, the uninformed seller may never realize the quality of the good that he sold. This renders conventional warranties and some of the other market and legal solutions to the lemons problem ineffective in the gems case. We explore the way in which screening, signaling, legal duties, auctions, and keeping experts off the market may mitigate an inverse adverse-selection problem.
\end{abstract}

JEL codes: D44, D82, D86, K12.

Keywords: lemons, gems, adverse selection, asymmetric information, auction

\footnotetext{
*The authors would like to thank___ for helpful comments.

${ }^{\dagger}$ University of Amsterdam (ACLE) and Tinbergen Institute; gdarimat@uva.nl; SSRN author page http://ssrn.com/author=333631. The financial support by the NWO grant 016.075.332 is gratefully acknowledged.

${ }_{\ddagger}$ University of Amsterdam and Tinbergen Institute; onderstal@uva.nl; SSRN author page http://ssrn.com/author $=342318$. The financial support by the NWO grant 453.03 .606 is gratefully acknowledged.

$\S$ University of Minnesota - Twin Cities - School of Law and University of Bologna, Department of Economics; parisi@umn.edu; SSRN author page http://ssrn.com/author=227722.
} 


\section{Introduction}

An asymmetry of information arises whenever participants in a transaction can rely on different information relevant to their contract or relationship. In his 1970 article "Market for Lemons", George Akerlof illustrated this concept and considered the impact of asymmetric information in the used-car market - a market where sellers are likely to know more about the quality of the goods traded than buyers. When buyers cannot ascertain the quality of a used car, uncertainty depresses prices. Owners of high-quality cars consequently become less likely to put their good-quality car on the market at the depressed price and the market will be predominantly populated by low-quality used cars (lemons). This will further reduce the expected quality of the cars that remain on the market and their price and will drive additional prospective sellers out of the market. This process, known as "adverse selection," leads to a market failure because sellers exploit their informational advantage over buyers by only putting on the market goods that are of lower quality than the price. If both parties were uninformed, the market would function better, as sellers would not be able to withdraw high-quality cars from the market and all cars would be sold for an average price, reflecting the possibility that a car be of low or high quality. As it is well-known, the problems of asymmetric information extend well beyond used-car markets and applications to other markets - such as insurance or labor markets - abound. However, applications of this principle have preserved the original focus on transactions between informed sellers and uninformed buyers.

This paper illustrates and examines the dual problem that occurs when buyers, rather than sellers, possess private information. This might be the case for goods of uncertain value, such as artworks, or for sales between an expert buyer and a one-time seller, such as a real estate investor and a homeowner, or a diamond expert and an individual seller. In this case, sellers find themselves in a situation that mirrors that of buyers in the lemons market. Sellers may be induced to ask very high prices, suspecting that if an (informed) buyer shows interest in what they are selling, the good that is being sold must have some hidden quality of which they are not aware. To paraphrase Akerlof's description, we shall therefore refer to this case as the "market for gems" problem. As in Akerlof's model, the market for gems may shrink or entirely collapse. These two variants of adverse selection are dual to one another and are both detrimental to social welfare compared to the ideal world in which both sellers and buyers are informed about the quality of goods and where prices reflect quality.

While the standard case of adverse selection with uninformed buyers has been extensively analyzed, the inverse case of adverse selection with uninformed sellers has received virtually no attention in the economic literature. In the following, we unveil the dualities between the lemons and gems markets and explore the economic consequences of this case of asymmetric information, which we shall refer as "inverse adverse selection." In Section 2, we develop a dual model of adverse selection to inquire whether the theoretical symmetry between these two problems extends to their effects. In Subsection 2.3, we show that, unlike in the lemons market, in the gems market the selection affects low-quality goods, 
leaving only high-quality goods on the market and pushing up prices. The race to the bottom in quality and prices observed in the lemons market turns into a race to the top in both quality and prices in the gems market. As we will argue, asymmetries might arise at two levels. In the lemons market, the uninformed buyer is likely to find out about the real quality of the good as time passesthe car breaks down, the employee is less productive than average, the insured party exhibits its high-risk profile - and can easily provide evidence for it. In the lemons market, the price-quality mismatch materializes in a defect that becomes observable by the buyer after the transaction and is possibly verifiable in court. In contrast, in the gems market, the uninformed seller does not necessarily find out about the hidden qualities of the sold item after the transaction and might not be able to prove the price-quality mismatch after the fact. In Section 3, we compare the results obtained in a model of markets characterized by asymmetric information to those obtained when parties are symmetrically misinformed. We identify the conditions under which asymmetric information is preferable to the case of no information.

In Section 4, we explore the viability of traditional mechanisms to solve the asymmetric information problem when sellers, rather than buyers lack information. In the standard adverse selection model, the informed seller possesses information and has incentives to signal the content of its knowledge about the positive attributes of the good or service to prospective buyers. The negative attributes will not be revealed by informed sellers and it may be in the interest of buyers to invest in screening to identify such negative attributes. The opposite is true in the case of inverse adverse selection. Here, the informed buyer possesses information and has incentives to signal his information about the negative attributes of the good or service to prospective sellers. The positive attributes will not be revealed by informed buyers and it will instead be in the interest of sellers to invest in screening to identify such positive attributes prior to the transaction. Signaling and screening strategies will thus be undertaken by different parties and reveal information of opposite content in the two situations. We also study other solutions to the uninformed seller problem, including affirmative duties to disclose information, auctions, and closing the market for expert buyers. Our analysis reveals relevant differences in the application of these solutions to the two variants of adverse selection considered in this paper. For example, auctions are often advocated to elicit information from buyers and are therefore ill-suited to solve traditional market-for-lemons problems. In our framework, instead, they may prove useful to solve market-for-gems problems.

Legal systems also seem to react differently to the two types of asymmetric information. For example, seller's asymmetric-information problems are often addressed by creating affirmative duties to disclose information or by providing legal warranties for hidden defects. Instead, legal systems have been more parsimonious in addressing buyer's asymmetric-information problems. In Section 4, we further consider the implications of creating affirmative duties to disclose information to avoid inverse-adverse-selection problems or creating legal warranties for hidden qualities to correct market-for-gems problems. We examine these issues and provide an explanation of the observed irregularities in the 
treatment of information asymmetries. Section 5 concludes.

\section{Dual models of adverse selection: lemons and gems}

We will consider a setting in which a seller (she) owns an object which is worth $v_{S}$ to her while a potential buyer (he) assigns value $v_{B}$ to it. In this section, we will study the effects of incomplete information about the value of the object on either the buyer's side (the lemon's case) or the seller's side (the gem's case). We examine these two cases in sections 2.1 and 2.2 , respectively. In order to emphasize that these two situations are each other's mirror image, we have kept the set-up of these two sections as similar as possible.

\subsection{Adverse selection: the market for lemons}

Suppose that the seller is informed about her value $v_{S}$, while the buyer is not. We assume that $v_{S}$ is distributed with differentiable cumulative distribution function $F_{S}$ on $\left[\underline{v}_{S}, \bar{v}_{S}\right]$. The buyer value is $v_{B} \equiv b\left(v_{S}\right)$. The seller sells at price $p$ if $v_{S} \leq p$. Consequently, the buyer buys if the average value of the goods offered for sale on the market $b^{*}(p)$ is larger than the price $p$, where $b^{*}(p)$ can be expressed as

$$
b^{*}(p) \equiv E\left\{b\left(v_{S}\right) \mid v_{S} \leq p\right\}=\frac{\int_{\underline{v}_{S}}^{p} b(v) d F_{S}(v)}{F_{S}(p)}
$$

Because only those sellers with lower valuation than the market price will sell, trade is only feasible for $v_{S} \in\left[\underline{v}_{S}, p^{B}\right]$, where

$$
p^{B}=\max \left\{p \in\left[\underline{v}_{S}, \bar{v}_{S}\right] \mid p \leq b^{*}(p)\right\}
$$

Note that high-value goods are not traded on the market. Conditional on trade at price $p^{B}$, the expected gains from trade for the buyer are $b^{*}\left(p^{B}\right)-p^{B}=$ 0 ; note that a buyer might make a loss or a gain in specific cases, as he does not know the real value of the good but only the average value. In contrast, in the case of trade, a seller with valuation $v_{S}$ always makes a gain $p^{B}-v_{S}>0$. The expected gains from trade for sellers are

$$
\int_{\underline{v}_{S}}^{p^{B}}\left(p^{B}-v_{S}\right) d F_{S}(v)=F_{S}\left(p^{B}\right)\left[p^{B}-\tilde{v}_{S}\right] .
$$

where $\tilde{v}_{S} \equiv E\left\{v_{S} \mid v_{S} \leq p\right\}$ is the average seller valuation of the goods on the market.

Proposition 1 (Market for lemons). If the seller has complete information and the buyer does not, trade will be feasible only for goods with low seller valuation $v_{S} \in\left[\underline{v}_{S}, p^{B}\right]$. 
Figure 1 illustrates these findings.

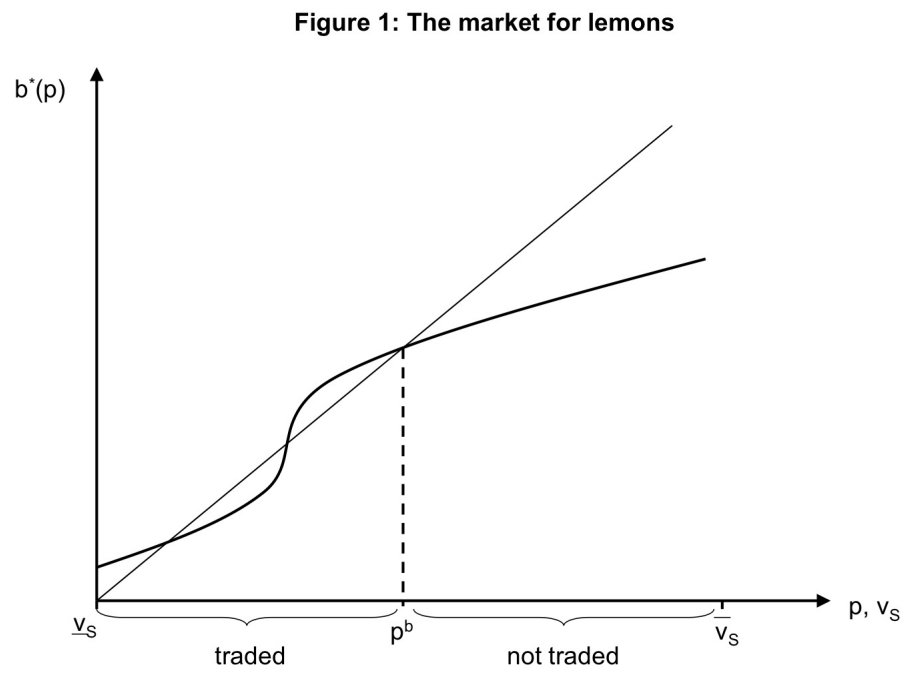

The following example further illustrates the above results.

Example 2. Suppose that $v_{S} \sim U[0,1]$ and $v_{B}=b\left(v_{S}\right)=\alpha+(1-\alpha) v_{S}$, $\alpha \in[0,1]$. Trade is feasible iff

$$
\begin{aligned}
b^{*}(p) & =E\left\{b\left(v_{S}\right) \mid v_{S}<p\right\} \\
& =E\left\{\alpha+(1-\alpha) v_{S} \mid v_{S}<p\right\} \\
& =\alpha+\frac{(1-\alpha) p}{2} \\
& \geq p
\end{aligned}
$$

which is equivalent to

$$
p \leq \frac{2 \alpha}{1+\alpha} .
$$

Therefore, there will be trade only if

$$
v_{S} \in\left[0, \frac{2 \alpha}{1+\alpha}\right]
$$

i.e., in at most a fraction $\frac{2 \alpha}{1+\alpha}$ of the cases.

The next example shows that there may be no trade at all in the market for lemons even if this is always efficient.

Example 3. Assume $v_{S} \sim U[0,1]$ and $v_{B}=b\left(v_{S}\right)=\beta v_{S}, \beta \in[1,2)$. Trade is 
feasible iff

$$
\begin{aligned}
b^{*}(p) & =E\left\{b\left(v_{S}\right) \mid v_{S}<p\right\} \\
& =E\left\{\beta v_{S} \mid v_{S}<p\right\} \\
& =\frac{\beta p}{2} \\
& \geq p
\end{aligned}
$$

which is a contradiction to the assumption that $\beta<2$ and the fact that trade will only take place if $p>0$. Therefore, the market will collapse.

\subsection{Inverse adverse selection: the market for gems}

Suppose that the buyer is informed about his value $v_{B}$, while the seller is not. We assume that $v_{B}$ is distributed with differentiable cumulative distribution function $F_{B}$ on $\left[\underline{v}_{B}, \bar{v}_{B}\right]$. The seller value is $v_{S} \equiv s\left(v_{B}\right)$. The buyer buys at price $p$ if $v_{B} \geq p$. Consequently, the seller sells if the average value of goods that buyers are willing to buy on the market $s^{*}(p)$ is smaller than $p$, where $s^{*}(p)$ can be expressed as

$$
s^{*}(p) \equiv E\left\{s\left(v_{B}\right) \mid v_{B} \geq p\right\}=\frac{\int_{p}^{\bar{v}_{B}} s(v) d F_{B}(v)}{1-F_{B}(p)} .
$$

Because only those buyers with higher valuations than the market price will buy, trade is only feasible for $v_{B} \in\left[p^{S}, \bar{v}_{B}\right]$, where

$$
p^{S}=\min \left\{p \in\left[\underline{v}_{B}, \bar{v}_{B}\right] \mid p \geq s^{*}(p)\right\}
$$

Note that now low-value goods are not traded in the market. Conditional on trade at price $p^{S}$, the expected gains from trade are $p^{S}-s^{*}\left(p^{S}\right)=0$ for the seller; note that the seller might occasionally make a loss or a gain, as she does not know the real value of the good but only the average value. In contrast, in the case of trade, a buyer with valuation $v_{B}$ always makes a gain $v_{B}-p^{S}>0$. The expected gains from trade for buyers are

$$
\int_{p^{S}}^{\bar{v}_{B}}\left(v_{B}-p^{S}\right) d F_{B}(v)=\left[1-F_{B}\left(p^{S}\right)\right]\left[\tilde{v}_{B}-p^{S}\right] .
$$

where $\tilde{v}_{B} \equiv E\left\{v_{B} \mid v_{B} \geq p^{S}\right\}$ is the average buyer valuation of the goods on the market.

Proposition 4 (Market for gems). If the buyer has complete information and the seller does not, trade will be feasible only for goods with high buyer valuation $v_{B} \in\left[p^{S}, \bar{v}_{B}\right]$.

Figure 2 illustrates these findings. 
Figure 2: The market for gems

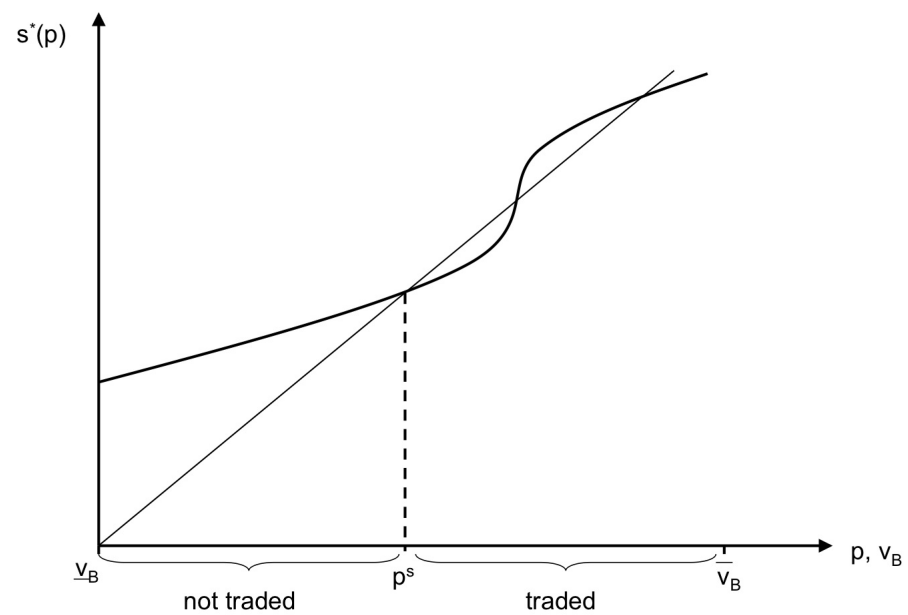

The following example further illustrates the above results.

Example 5. Suppose that $v_{B} \sim U[0,1]$ and $v_{S}=s\left(v_{B}\right)=(1-\alpha) v_{S}, \alpha \in[0,1]$. Trade is feasible iff

$$
\begin{aligned}
s^{*}(p) & =E\left\{s\left(v_{S}\right) \mid v_{B}>p\right\} \\
& =E\left\{(1-\alpha) v_{B} \mid v_{B}>p\right\} \\
& =\frac{(1-\alpha)(1+p)}{2} \\
& \leq p
\end{aligned}
$$

which is equivalent to

$$
p \geq \frac{1-\alpha}{1+\alpha}
$$

Therefore, there will be only trade if

$$
v_{B} \in\left[\frac{1-\alpha}{1+\alpha}, 1\right]
$$

i.e., in at most a fraction $\frac{2 \alpha}{1+\alpha}$ of the cases.

The next example shows that, like in the market for lemons, there may be no trade at all in the market for gems even if this is always efficient.

Example 6. Assume $v_{B} \sim U[0,1]$ and $v_{S}=s\left(v_{B}\right)=1+(\beta-1)\left(v_{B}-1\right)$, 
$\beta \in[1,2)$. Trade is feasible iff

$$
\begin{aligned}
s^{*}(p) & =E\left\{s\left(v_{B}\right) \mid v_{B}>p\right\} \\
& =E\left\{1+(\beta-1)\left(v_{B}-1\right) \mid v_{B}>p\right\} \\
& =1-\frac{1}{2}(\beta-1)(1-p) \\
& \leq p
\end{aligned}
$$

which is a contradiction to the assumption that $\beta<2$ and the fact that trade will only take place if $p<1$. Therefore, the market will collapse.

\subsection{Dualities in adverse selection}

From the analysis of the previous sections it is straightforward to notice that adverse selection and inverse adverse selection are dual problems. Table 1 below illustrates this point.

\begin{tabular}{|l|l|l|}
\hline & Adverse selection & Inverse adverse selection \\
\hline \hline \multirow{2}{*}{ Buyer } & $\begin{array}{l}\text { Uninformed } \\
\text { Buyer's valuation } b\left(v_{S}\right)\end{array}$ & $\begin{array}{l}\text { Informed } \\
\text { Buyer's valuation } v_{B}\end{array}$ \\
\hline \multirow{2}{*}{ Seller } & $\begin{array}{l}\text { Informed } \\
\text { Seller's valuation } v_{S}\end{array}$ & $\begin{array}{l}\text { Uninformed } \\
\text { Seller's valuation } s\left(v_{B}\right)\end{array}$ \\
\hline \multirow{2}{*}{ Market } & $\begin{array}{l}\text { Size of the market: } F_{S}\left(p^{B}\right) \\
\text { Disappears for high-value goods }\end{array}$ & $\begin{array}{l}\text { Size of the market: } 1-F_{B}\left(p^{S}\right) \\
\text { Disappears for low-value goods }\end{array}$ \\
\hline \multirow{2}{*}{ Goods on the market } & Low-value goods $($ lemons $)$ & $\begin{array}{l}\text { High-value goods }(\text { gems }) \\
\text { Price: } p^{S}=s^{*}\left(p^{S}\right)\end{array}$ \\
\hline Buyer's surplus & Price: $p^{B}=b^{*}\left(p^{B}\right)$ & Positive: $\left[1-F_{B}\left(p^{S}\right)\right]\left[\tilde{v}_{B}-p^{S}\right]$ \\
\hline Seller's surplus & Pero & Zero \\
\hline
\end{tabular}

Table 1: Dualities in adverse selection

If one assumes that the functions $b$ and $s$ are strictly increasing and continuous, there is a direct one-to-one relationship between the adverse selection and inverse adverse selection models, in the sense that one can transform a problem into its dual and vice versa in the following way:

Proposition 7 (Duality). If the functions $b$ and $s$ are strictly increasing and continuous, adverse selection and inverse adverse selection are dual problems with $s=b^{-1}$ and $F_{B}(v)=P\left\{v_{B} \leq v\right\}=P\left\{b\left(v_{S}\right) \leq v\right\}=P\left\{v_{S} \leq b^{-1}(v)\right\}=$ $F_{S}\left(b^{-1}(v)\right)$.

The hypothesis of strictly increasing and continuous functions implies that there a positive correlation between them. Higher quality goods are more valuable to both buyers and sellers, not withstanding their different subjective valuations of the good. 


\section{Symmetric misinformation versus asymmetric information}

In this section, we compare the results of markets characterized by both types of asymmetric information (adverse selection and inverse adverse selection) with those obtained in markets where participants are symmetrically misinformed (where both parties are incompletely informed about value). In our model, the lack of information implies that parties may occasionally enter into transactions that prove to be undesirable. This is because we allow for the buyer's valuation to be below the seller's valuation. Therefore, we can distinguish between two types of transactions: desirable transactions are those transactions concerning a good that the buyer values more than the seller-with $b\left(v_{S}\right)>v_{S}$, in the case of lemons, or $v_{B}>s\left(v_{B}\right)$, in the case of gems - while unwanted transactions are those transactions concerning a good that the buyer values less than the seller - with $b\left(v_{S}\right)<v_{S}$ or $v_{B}<s\left(v_{B}\right)$, respectively. If the valuations of buyers and sellers are equal, the transaction does not affect social welfare, but might be considered unwanted in the light of transaction costs saving.

Obviously, if both parties are informed, only desirable transactions can take place. With symmetric misinformation there is no filter on the transactions that occur. The surplus is given by the average buyer valuation minus the average seller valuation: $E\left(b\left(v_{S}\right)\right)-E\left(v_{S}\right)$, in the case of lemons, and $E\left(v_{B}\right)-E\left(s\left(v_{B}\right)\right)$, in the case of gems. The market is either complete (if the surplus is positive) or disappears altogether (if the surplus is negative). This implies that if the unwanted transactions outweigh the desirable transactions the market will disappear and no transaction will take place, including the desirable transactions. Otherwise, if the desirable transactions outweigh the unwanted transactions, the market will persist and all transactions, included the unwanted ones, will take place.

The surplus in markets with asymmetric information is given by the surplus of the informed party - because we have demonstrated that the uninformed party breaks even on average. As we have shown above, such surplus is always positive and is given by the number of transactions times the average surplus: $F\left(p^{B}\right)\left[p^{B}-\tilde{v}_{S}\right]$, in the case of lemons, and $\left[1-F\left(p^{S}\right)\right]\left[\tilde{v}-p^{S}\right]$, in the case of gems. With asymmetric information, at least one party can filter the transactions that go through and prevent some unwanted transactions from happening.

The balance between asymmetric information and symmetric misinformation depends on the comparison between these surpluses, which in turn depends on the prevalence and distribution of unwanted transactions in the market. Asymmetric information, although imperfectly, fulfills a matching function that symmetric misinformation is unable to fulfill: it takes out of the markets goods that most likely would result in an unwanted transaction.

Proposition 8 (Symmetric misinformation v. asymmetric information). Symmetric misinformation yields higher social welfare than asymmetric information if and only if $E\left(b\left(v_{S}\right)\right)-E\left(v_{S}\right)>\left[p^{B}-\tilde{v}_{S}\right] F\left(p^{B}\right)$, in the case of lemons, and if and only if $E\left(v_{B}\right)-E\left(s\left(v_{B}\right)\right)>\left[\tilde{v}-p^{S}\right]\left[1-F\left(p^{S}\right)\right]$, in the case of gems. 
The following two corollaries emphasize two subcases in which one type of lack of information is unambiguously better than the other. The first corollary points to those situations in which the buyer's valuation is always higher than the seller's valuation. In this case, symmetric misinformation lets all transactions go through, which is welfare improving. Instead, asymmetric information might forego some transactions or even all of them, although each transaction is welfare improving (as we have seen in the examples above). Thus, symmetric misinformation is to be preferred.

Corollary 9. Symmetric misinformation yields higher social welfare than asymmetric information (or the same level of social welfare) if $b\left(v_{S}\right) \geq v_{S}$ for all $v_{S} \in\left[\underline{v}_{S}, \bar{v}_{S}\right]$, in the case of lemons, or $v_{B} \geq s\left(v_{B}\right)$ for all $v_{B} \in\left[\underline{v}_{B}, \bar{v}_{B}\right]$, in the case of gems.

The second corollary, emphasizes the opposite case in which asymmetric information is unambiguously more beneficial to social welfare than symmetric misinformation. This occurs when the average buyer's valuation is less than the average seller valuation, like in the examples in Section 2. With symmetric misinformation the market will collapse and no transaction will take place. Instead, with asymmetric information some transactions might go through, thereby resulting in a higher level of social welfare.

Corollary 10. Asymmetric information yields higher social welfare than symmetric misinformation (or the same level of social welfare) if $E\left(b\left(v_{S}\right)\right) \leq$ $E\left(v_{S}\right)$, in the case of lemons, or $E\left(v_{B}\right) \leq E\left(s\left(v_{B}\right)\right)$, in the case of gems.

\section{Asymmetric solutions for symmetric problems}

Several practical solutions have been proposed for adverse selection including signaling, screening, and the legal obligation to reveal hidden information. In this section, we will argue that the mirror-images of those solutions are often more difficult to implement for inverse adverse selection. The reason lies in two sources of asymmetry between adverse selection and inverse adverse selection that exist despite the clear symmetry between the two problems. Table 2 illustrates this point.

\begin{tabular}{|c|c|c|}
\hline & Adverse Selection & Inverse Adverse Selection \\
\hline \hline $\begin{array}{c}\text { Source of hidden information } \\
\text { information by the uninformed party }\end{array}$ & Use & Expertise \\
\hline Reason for information asymmetry & $\begin{array}{c}\text { Role in the purchase } \\
\text { (buyer / seller) }\end{array}$ & $\begin{array}{c}\text { Identity of the party } \\
\text { (expert / layman) }\end{array}$ \\
\hline $\begin{array}{c}\text { Ex ante detection of hidden } \\
\text { information by the uninformed party }\end{array}$ & Easy & Difficult \\
\hline
\end{tabular}

Table 2: Asymmetries in asymmetric information problems 
The first asymmetry originates from differences in the ability of the uninformed party to acquire information on the quality of the good after the purchase. In the case of lemons, the buyer will plausibly sooner or later find out whether the good he purchased has the promised qualities or not. The problem with lemons is not that such information is unavailable, rather, the problem is that it is unavailable to the buyer at the time of the purchase. In contrast, in the case of gems, the seller of a good of higher quality than expected might find it difficult to gather information about its actual value; that is, the relevant information might never become available because it does not derive from use but from specific expertise. Given that the seller did not have such information before the sale, it is not very likely that he will acquire it later. In the case of lemons, information acquisition follows from possession and use of the good purchased by the uninformed buyer, while this mechanism does not apply to the uninformed seller of a gem. This implies that asymmetric information in gems markets is likely to be more persistent over time than in lemons markets; that is, gems problems are more difficult to amend ex post.

A second source of asymmetry emerges from buyers plausibly having more information than sellers on some characteristics of the goods they sell simply because buyers have had more time to experience the good. Therefore, in a gems market, it is less obvious that sellers have an informational advantage than in a lemons market. The informational advantage of sellers depends on the specific abilities of a seller and on specific investments in research that he might have made. Thus, lemons problems are more easily detected at the outset than gems problems, which might be more heavily related to the identity of the buyer. All in all, gems markets generate more insidious problems but, precisely because less observable, might also leave smaller traces in the legal system and in contracting practices.

In the following, we will briefly consider the applicability of traditional solutions to the adverse selection problem in the context of our inverse adverse selection problem. In particular, we will discuss signaling, screening, and legal duties to disclose in Sections 4.1, 4.2, and 4.3 respectively. Furthermore, we will discuss two solutions that are likely to work better for gems markets than for lemons markets: (procurement) auctions in Section 4.4 and keeping experts out of the market in Section 4.5. Table 3 illustrates those solutions and indicates their practical applicability.

\begin{tabular}{|c|c|c|}
\hline & Adverse Selection & Inverse Adverse Selection \\
\hline \hline Signaling & Warranties $(++)$ & Inverse-Warranties $(+/-)$ \\
\hline Screening & Price Discrimination $(+)$ & Price Discrimination $(+/-)$ \\
\hline Legal Solutions & Duties to Disclose Hidden Defects $(+)$ & Duties to Disclose Hidden Qualities $(+/-)$ \\
\hline Competition & Procurement Auctions $(+/-)$ & Auctions $(++)$ \\
\hline Other market solutions & Keeping experts out of the market $(-)$ & Keeping experts out of the market $(-)$ \\
\hline
\end{tabular}

Table 3: Solutions to adverse selection problems 
Notes:,,$--+/-,+.++$ indicate that the solution has very low, low, unclear, high, very high practical applicability respectively

\subsection{Signaling: Inverse warranties}

In a market where prospective buyers, rather than sellers, have private information about the quality of the goods, the functioning of signaling solutions is reversed. Mirroring the lemons market, where informed sellers rationally withhold negative information from their buyers, in a gems market, informed buyers rationally withhold private information on the qualities of the goods they wish to acquire from uninformed sellers. The operation of signaling is similarly reversed. If prospective buyers can credibly convey negative information to their uninformed sellers (e.g., if a diamond expert can convince a prospective seller about the existence of a defect in the stone), a lower purchase price could be obtained. Signaling negative information is therefore in the interest of a rational informed buyer.

The ways in which such signaling can materialize requires some creative thinking. In a market for lemons, sellers can signal the high quality of the goods by offering a warranty or giving unsatisfied customers a right to withdraw from the contract and return the good. The equivalent signaling solution for our inverse adverse-selection problem would consist in offering an inverse warranty. The inverse warranty would specify that if after the sale a seller is unsatisfied with the terms of the sale because positive information is discovered, revealing that the value of the good was above a certain amount, the seller could demand rescission of the sale (the equivalent of the buyer's right to withdraw, in the lemons problem) or obtain an increase in the price. For such an inverse warranty to serve as a signaling device, the terms of the warranty should be such as to create a separating equilibrium between low-valuing and high-valuing buyers. Only buyers who know the quality of the good to be low should be willing to offer an inverse warranty to their sellers.

However, implementing such form of inverse warranty may also prove difficult, given the difficulty for a seller to ascertain the true value of the good after the good has been transferred to the buyer. Further, engaging in this form of signaling may provide adverse incentives for informed and uninformed buyers alike. Buyers of gems know that if positive information is discovered, their sellers would likely exercise the inverse warranty. This would dissipate the surplus from their purchase. Informed buyers could therefore engage in costly activities to suppress or conceal positive information from their sellers. For example, a valuable piece of art may not be publicly displayed or may not be publicly resold to avoid the transmission of positive information to the original seller. Uninformed buyers may also face distorted incentives. For example, a buyer that lacked private information on the quality of the good may delay owner-specific investments, fearing that positive information may become available, triggering the seller's right to demand restitution. One additional way with which professional buyers might commit not to exploit sellers is by giving them a right on 
a percentage of the resale price, in case the good is sold to a third party. This mechanism is similar to the droit de suite, granted to artists or their heirs to receive a percentage of the resale price of their works of art.

\subsection{Screening: Price discrimination}

The design of screening mechanism to correct our inverse adverse selection problem follows a similar intuition as for signaling devices. With screening the uninformed party moves first and tries to harvest information from the informed party. In our case, the prospective seller could design offers in such a way that prospective buyers would self-select the offer that is best for them, which would then reveal their type in equilibrium. This could involve offering two alternative contracts, one of which for a lower sale price but with a buy-back option in favor of the current seller. By observing the choice of contract, the prospective seller could identify the type of buyer. Further, the uninformed seller could introduce contract terms designed to create incentives for the voluntary disclosure of private information. In our context, the uniformed party may introduce contract terms that only a high-valuing buyer would have an interest in changing. Alternative ways to carry out screening could involve the seller price discriminating between different types of buyers. One way in which this can be done is by attaching additional services to the good which only high-value buyers will buy.

\subsection{Affirmative duties to disclose}

Legal rules play an important role in preventing and correcting adverse selection problems. For example, in some cases legal rules are designed to create incentives for the voluntary disclosure of private information. This is the case of the information-forcing default rules $^{1}$ and the penalty default rules. ${ }^{2}$ In other situations, legal systems create affirmative duties to disclose private information that may negatively affect the value of the transaction to the other contracting party - e.g., disclosure of hidden defects of a product, disclosure of prior employment record, disclosure of preexisting health conditions. These legal duties can be used to force the disclosure of negative information by sellers to buyers in the traditional lemons problem.

In order to correct the asymmetric information problem that characterizes the gems problem, the legal duty should be extended to the disclosure of positive

\footnotetext{
${ }^{1}$ The concept of information-forcing default rules was first formulated by Goetz and Scott (1980) who suggested that some legal rules purposefully allocate the risk on the party that is in the best position to disclose information relevant to the transaction.

${ }^{2}$ Ayres and Gertner (1989) introduced the concept of penalty default rules as default rules that are designed to give at least one party an incentive to contract around them. By doing so penalty default rules encourage one or both parties to reveal information to the other party. An essential premise of the notion of penalty default rules is the idea that there may be strategic reasons for leaving a contract incomplete. Penalty default rules give parties incentives to negotiate ex ante by penalizing them for leaving inefficient gaps in their contracts. See also Bebchuk and Shavell (1991) for a different view.
} 
information by buyers to their sellers. However, legal systems have been reluctant to impose a general duty to disclose positive information on contracting parties. The rationale for this exclusion is that a general requirement to disclose positive information would undermine the prospective buyers' incentives to search for such information (Kronman, 1978). Resources would then be left in the hands of low-valuing uninformed parties, rather than being sought and efficiently reallocated through the search of informed treasure hunters. In addition to these problems, legal economists have warned against the use of legal solutions to correct for such market imperfections. The argument is that the respective role of market versus legal solutions to the adverse selection problem should be carefully evaluated inasmuch as legal intervention can occasionally curtail the effectiveness of market solutions - e.g., a law that imposes mandatory warranties would eliminate the signaling value of the warranty. These unintended consequences of legal intervention could be present also in the case of inverse adverse selection, creating a prejudice for the very people that the law intended to protect.

One additional difference between the use of legal duties to disclose in the market for lemons and market for gems originates from the different roles played by the uninformed parties after the sale. In the market for lemons, uninformed buyers have an opportunity to acquire information through the use of the good after the purchase. A dissatisfied buyer of a lemon could then exercise the legal protection offered by disclosure laws to rescind the sale or obtain damages or a price reduction. In the resulting lawsuit, the buyer has actual possession of the good and could more easily produce evidence of the (insufficient) quality of the good in support of his claim. In contrast, in the market for gems, the uninformed party plays the role of the seller. Upon conclusion of the sale, the seller loses possession of the good. This places him in a relatively disadvantaged position in the event of a lawsuit, given the difficulty to produce evidence on the undisclosed qualities of the good. In sum, affirmative duties to disclose negative information by sellers may be easier to enforce than affirmative duties to disclose positive information by buyers. Lemons problems are easier to correct through law than gems problems.

\subsection{Auctions and the role of market competition}

The inverse relationship between the lemons and the gems markets is particularly evident when considering the role of market competition. The main idea is that competition forces informed parties to reveal their private information. In order to use market competition to solve the standard lemons problem, competition would have to be fostered among informed sellers. In theory, this is what happens in a procurement auction, where informed sellers bid downwards to the advantage of potentially uninformed buyers. For an auction mechanism to be effective in a standard lemons problem, however, the sellers should compete revealing information over the same good, rather than similar goods sharing different individual characteristics. For this reason sellers' competition over homogeneous goods - e.g., sale of used memory cards of the same brand 
on eBay - could convey private information on the quality of the product, but would not convey private information that is peculiar to the specific item. For this reason, auctions are not generally enlisted as effective solutions for the traditional lemons problem. ${ }^{3}$

In contrast, auctions may effectively solve the inverse adverse selection problem. By competing in an auction, informed buyers are forced to reveal their valuations and the asymmetric information gap between buyers and sellers is filled. ${ }^{4}$ Even if sellers ignore the value of their goods, the auction will yield different prices for high-value and low-value goods and would make it possible for both types of goods to be be traded. Compared to the equilibrium observed in our market for gems, the auction would lead to a decrease in the average price (and average quality) of the goods traded in the market, but would lead to an expansion of the size of the market. Interestingly, the function of an auction in a market for gems is not to allow the sale of high-value goods at the highest price possible, but rather to allow the sale of low-value goods, which would otherwise be left out of the market, at a low price. Uninformed sellers would be willing to accept a low price for their good, without fear of being exploited by better informed buyers. Sellers would, in fact, be able to infer that the low price generated by the auction for their goods reflects the low quality of their goods and, based on this information, they would choose to sell rather than withdraw from the market.

\subsection{Restoring symmetry: Keeping experts out of the mar- ket}

Both the lemons and the gems problems are caused by asymmetric information. The solutions considered in the previous sections are aimed at correcting the asymmetry by giving information - through signaling, screening, mandatory disclosure, or competition - to the uninformed party. However, solving the asymmetric information problem does not necessarily require making both parties informed. At times, the problem may be corrected by suppressing the informational advantage of the informed party. In the standard lemons problem this solution cannot be easily implemented. Most sellers know the experience qualities of their goods and their information cannot easily be suppressed. In the market for gems, the problem is caused by the fact that some expert buyers have an informational advantage. The presence of experts makes the market shrink and might reduce welfare. Symmetry could be restored by keeping expert buyers out of the market. The implementation of this solution may lead to the creation of two markets, one where experts are not admitted and another open to all buyers; noninformed parties would naturally keep out of the latter market. This would lead to two markets with full size: one characterized by symmetric misinformation, where uninformed sellers sell to uninformed buyers, and another characterized by symmetric information, in which expert sellers

\footnotetext{
${ }^{3}$ Manelli and Vincent (1995) show that under certain conditions, the buyer is better off by bargaining with an individual seller than by running a procurement auction.

${ }^{4}$ See Krishna (2009) for an overview of auction theory.
} 
would meet with expert buyers. However, as we have already noted, it is often difficult to detect ex ante whether a buyers in a gems market has private information on the good he is trying to buy, whether this can be easily inferred for sellers in a lemons market. Therefore, this solution might be difficult to implement in practice.

\section{Conclusions}

This paper analyzes the mirror image of Akerlof's lemons model: inverse adverse selection in the market for gems. We have shown that the two problems are symmetric - in fact, under certain conditions, the market for gems is the dual of the market for lemons. In both cases, an informed party benefits from private information, adversely affecting the uninformed party. In the standard case of adverse selection, market transactions only involve low-value goods. Instead, in the mirror-image case of inverse adverse selection, only high-value goods are traded.

Despite the symmetry between adverse selection and inverse adverse selection, the two problems generate asymmetric consequences for real-life markets and they might require different solutions. The main difference between the adverse selection problem and the inverse adverse selection problem is that informed sellers are easy to detect (as they mostly acquire private information through use) and the asymmetry in information is usually remedied with time, since the buyer will acquire the same information as time passes. Consequently, uninformed buyers in a market for lemons know they are buying at a disadvantage and will at some point acquire the relevant information and get the available legal protection (for instance, enforce a warranty).

In contrast, informed buyers are more difficult to detect (as private information derives from expertise, not from use) and the asymmetry in information is not easily remedied, since the seller loses the good and does not necessarily receives further information about its value in the future. Therefore, uninformed sellers in a gems market are at a disadvantage both with respect to figuring our they are trading with a better informed party and with respect to obtaining possible legal protection, as they may never realize they sold for a price that was too low.

These asymmetries suggest that inverse adverse selection is both more insidious and more difficult to solve in practice and can be used to justify the different implementation of contractual and legal solutions to these two, otherwise symmetric, problems. We have analyzed solutions that involve screening, signaling, duties to disclose, auctions, and keeping experts out of the market. While for the lemons problem, signaling and screening seem to be the best practical solutions, for the gems problem, auctions seem to be the way to go. 


\section{References}

[1] Akerlof, George (1970), "The Market for Lemons: Qualitative Uncertainty and the Market Mechanism," 84 Quarterly Journal of Economics, 488-500.

[2] Ayres, Jan and Gertner, Robert H. (1989), "Filling Gaps in Incomplete Contracts: An Economic Theory of Default Rules," 99 Yale Law Journal, 87-130.

[3] Bebchuk, Lucian Arye and Shavell, Steven (1991), "Information and the Scope of Liability for Breach of Contract: The Rule of Hadley v. Baxendale," 7 Journal of Law, Economics, and Organization, 284-312.

[4] Goetz, Charles J. and Scott, Robert E. (1980), "Enforcing Promises: An Examination of the Basis of Contract," 89 Yale Law Journal, 1261-1322.

[5] Krishna, Vijay (2009), Auction Theory: Second Edition, New York: Academic Press.

[6] Kronman, Anthony T. (1978), "Mistake, Disclosure, Information, and the Law of Contracts," 7 Journal of Legal Studies, 1-34.

[7] Manelli, Alejandro M. and Vincent, Daniel R. (1995), "Optimal Procurement Mechanisms," 63 Econometrica, 591-620 